\title{
UTILIZAÇÃO DA TÉCNICA DO FURO CEGO PARA REDUÇÃO DE TENSÕES CRÍTICAS*
}

\author{
Aislan José Felipe Faustino ${ }^{1}$ \\ Filipe Otávio Nunes Ouverney ${ }^{2}$ \\ Gabriel Castro Ribeiro Ferreira e Silva ${ }^{3}$ \\ Guilherme de Souza Carvalho ${ }^{4}$ \\ Rafael Oliveira Santos ${ }^{5}$ \\ Luiz Henrique Dias Alves ${ }^{6}$
}

\section{Resumo}

O trabalho consiste na avaliação das Tensões Residuais através da técnica dos Furos-Cegos. O componente em estudo consiste em chapas de Aço A36 aplicadas para compor a estrutura de prensas hidraulicas. Com auxílio do software Solid Works versão 2013, foi realizado a simulação do estado de tensões sofridos pelas chapas quando a prensa hidraulica encontra-se em trabalho, determinando assim o seu fator de segurança. Em seguida, pelo método da aproximação sucessiva, foi adicionado furos-cegos ou furos passantes com diâmetros variados ao longo da geometria das chapas a fim de verificar o comportamento dos estados de tensões. Portanto, através da aplicação de furos-cegos nas chapas, foi possível identificar o diâmetro e posição ideal que permitiu um ganho significativo no fator de segurança das chapas, permitindo assim, reduzir o número de chapas no processo impactando diretamente nos custos e no tempo de fabricação do equipamento.

Palavras-chave: Furos-cegos, Tensões Residuais, Fator de Segurança.

\section{USE OF THE BLIND-HOLE DRILLING TECHNIQUE FOR REDUCING CRITICAL STRESSES}

\section{Abstract}

This study is an evaluation of Residual Stresses through the Blind-Hole Drilling technique. The component under study consists of A36 Steel Plate used to form the structure of hydraulic presses. With the help of Solid Works version 2013 software, a simulation was conducted of the stress state the plates undergo when the hydraulic press is in operation, thus determining its safety factor. Then, using the incremental drilling method, blind-holes or through-holes with varying diameters were added along the geometry of the plates in order to verify the behavior of the stress states. Through the application of blind-holes in the plates, it was therefore possible to identify the ideal diameter and position that permitted a significant increase in the safety factor of the plates, thus reducing the number of plates in the process, directly affecting equipment cost and manufacturing time.

Keywords: Blind-Hole Drilling, Residual Stress, Safety Factor.

\footnotetext{
Engenheiro de Produção, Pós Graduado em Processos de Produção e Manutenção- UFJF, 2015.

Engenheiro Mecânico, Pós Graduado em Processos de Produção e Manutenção- UFJF, 2015.

Engenheiro de Produção, Pós Graduado em Processos de Produção e Manutenção- UFJF, 2015. Engenheiro Metalúrgico, Pós Graduado em Processos de Produção e Manutenção- UFJF, 2015. Engenheiro de Produção, Pós Graduado em Processos de Produção e Manutenção- UFJF, 2015.

Engenheiro Metalúrgico, Mestre em Engenharia Mecânica(USP, 2000) e Doutor em Engenharia Mecânica, (FEG- UNESP, 2010). Professor Adjunto IV do departamento de Engenharia de produção e Mecânica da UFJF. Coordenador do Curso de Engenharia de Produção.
} 


\section{INTRODUÇÃO}

Os furos-cegos são pequenos orifícios circulares usinados em materiais que possuem diâmetro $D$ apropriado. A técnica em aplicar furos-cegos em estruturas de materiais com geometrias diversas consiste, na maioria das situações, em determinar as tensões residuais envolvidas no processo (PEIXOTO FILHO, 2004).

As prensas hidráulicas são equipamentos destinados à realização de cortes, dobras e modelagem de materiais como metal. São constituídas em sua maioria em um corpo com base para as chapas, para os cilindros hidráulicos e batentes de prensagem. Normalmente trata-se de um conjunto robusto com peso elevado. Para redução de peso e, conjuntamente, do custo de fabricação, foi elaborado um sistema composto de chapas em formato de aletas (PEIXOTO FILHO, 2004).

O estudo baseia-se na aplicação de furos-cegos em aletas envolvidas no processo a fim de verificar o seu comportamento em serviço. O resultado desta técnica levou a um significativo ganho na capacidade dessas chapas suportarem tensões axiais.

Portanto, com a aplicação desta técnica foi possível reduzir a quantidade de chapas utilizadas no equipamento em $20 \%$ impactando diretamente no custo de fabricação.

\section{REFERENCIAL TEÓRICO}

\subsection{Tensões Residuais}

Tensões residuais são aquelas que permanecem em um componente mesmo depois de cessadas as forças externas anteriormente aplicadas (DIETER, 1976). Estas tensões são elásticas e superpõe às cargas de serviços, podendo ser benéficas ou deletérias às estruturas e equipamentos, dependendo de sua magnitude, sinal e distribuição. Qualquer perturbação como remoção de material, aplicação de carregamentos térmicos ou mecânicos, altera seu estado e causa sua redistribuição de modo que as tensões se equilibrem novamente (www.puc-rio.com.br Acessado em: 05 de maio de 2015). Segundo Dieter (1976), este estado de tensões é autoequilibrante e, portanto, a resultante de forças e de momentos que as tensões residuais produzem é zero. Em várias situações, as tensões residuais são apontadas como principal causa de falhas em equipamentos.

\subsubsection{Tipos de Tensões Residuais}

A classificação mais comum das tensões residuais é quanto à área de abrangência, sendo elas divididas em três tipos: Tensões Residuais macroscópicas, Tensões Residuais microscópicas ou microestrutural e Tensões Residuais microlocalizada ou submicroestrural (PEIXOTO FILHO, 2004).

\subsubsection{Tensões Residuais Macroscópicas}

Também chamadas de tensões do tipo I, são tensões que se estendem ao longo do componente por vários grãos. Estas são provenientes de condições ou fontes mecânicas, térmicas ou químicas que afetam volume considerável do material. As tensões permanecem equilibradas por todo o corpo e têm sua origem em deformações plásticas macroscópicas. (DIETER, 1976). 


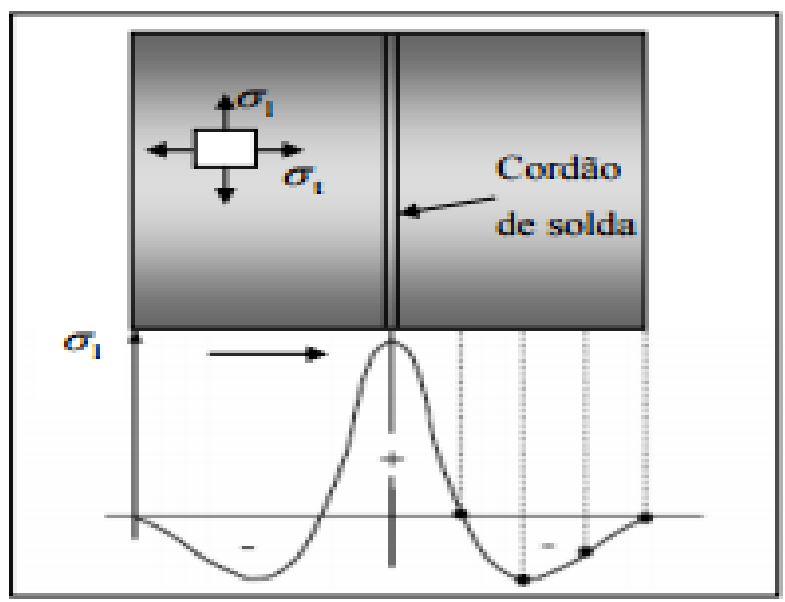

FIGURA 1 - Esquema do comportamento das tensões residuais nas vizinhanças de um cordão de solda. Fonte: Adaptado Site PUC-RJ.

\subsubsection{Tensões Residuais Microscópicas ou Microestrutural}

Também chamadas de tensões residuais do tipo II, são tensões que mantém uma distribuição uniforme ao longo de um grão ou de boa parte dele. Pode ocorrer em interfaces entre fases e partículas precipitadas e a matriz. Desenvolvem-se durante a deformação elastoplástica de um material policristalino com grãos aleatoriamente orientados e cuja resistência ao escoamento e encruamento dependem da orientação cristalográfica (www.puc-rio.com.br Acessado em: 05 de maio de 2015).

\subsubsection{Tensões Residuais microlocalizada ou submicroestrutural:}

Conhecidas como tensões residuais do tipo III, as tensões residuais submicroestrutural abrangem distâncias interatômicas, dentro de uma pequena porção de um grão. Ocorrem nos materiais metálicos sujeitos a processos que produzam descontinuidades na rede cristalina como vazios, impurezas, falhas de empilhamentos, entre outros (www.puc-rio.com.br Acessado em: 05 de maio de 2015).

\subsubsection{Processos geradores de Tensões Residuais}

Sob o ponto de vista do comportamento mecânico dos materiais pode-se dizer que "as tensões residuais aparecem como uma resposta elástica do material a uma distribuição não homogênea de deformações plásticas, precipitações, transformação de fase, deformação devido à expansão térmica, entre outros", (www.puc-rio.com.br Acessado em: 05 de maio de 2015). A Tabela 1 apresenta alguns mecanismos de geração de tensões residuais. 
TABELA 1 - Pesquisa qualitativa versus pesquisa quantitativa. (Fonte: Elaborado pelo Autor)

\begin{tabular}{|c|c|c|c|c|c|}
\hline 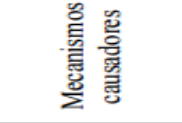 & \multirow[t]{2}{*}{$\begin{array}{l}\text { Deformação } \\
\text { mecânica } \\
\text { diferencial }\end{array}$} & \multirow[t]{2}{*}{$\begin{array}{c}\text { Transformação } \\
\text { de fase do } \\
\text { material }\end{array}$} & \multirow{2}{*}{$\begin{array}{l}\text { Contração ou } \\
\text { expansão } \\
\text { térmica } \\
\text { diferencial }\end{array}$} & \multirow[t]{2}{*}{$\begin{array}{l}\text { Microestrutura } \\
\text { diferencial }\end{array}$} & \multirow[t]{2}{*}{$\begin{array}{l}\text { Desigualdades } \\
\text { estruturais }\end{array}$} \\
\hline $\begin{array}{c}\text { Processos } \\
\text { associados }\end{array}$ & & & & & \\
\hline Conformação & $\begin{array}{l}\text { Laminação, } \\
\text { estampagem, } \\
\text { forjamento, } \\
\text { extrusão, } \\
\text { estiramento }\end{array}$ & & & & \\
\hline $\begin{array}{c}\text { Conformação } \\
\text { superficial }\end{array}$ & $\begin{array}{l}\text { Shot peening, } \\
\text { martelamento }\end{array}$ & & & & \\
\hline Usinagem & $\begin{array}{l}\text { Torneamento, } \\
\text { plainamento, } \\
\text { fresamento, } \\
\text { retificação, } \\
\text { furação, } \\
\text { eletroerosão }\end{array}$ & & & & \\
\hline Soldagem & & \begin{tabular}{|l|l|}
$\begin{array}{l}\text { Todos os } \\
\text { processos }\end{array}$ \\
\end{tabular} & $\begin{array}{ll}\text { Todos } & \text { os } \\
\text { processos } & \\
\end{array}$ & & \\
\hline $\begin{array}{l}\text { Tratamentos } \\
\text { térmicos }\end{array}$ & & $\begin{array}{l}\text { Têmpera, } \\
\text { normalização }\end{array}$ & $\begin{array}{l}\text { Têmpera, } \\
\text { normalização }\end{array}$ & & \\
\hline Fundição & & & $\begin{array}{l}\text { Diferentes } \\
\text { seções } \\
\text { transversais, } \\
\text { grandes } \\
\text { dimensões } \\
\end{array}$ & & \\
\hline $\begin{array}{l}\text { Tratamentos } \\
\text { térmicos } \\
\text { superficiais }\end{array}$ & & & $\begin{array}{l}\text { Cementação, } \\
\text { nitretação }\end{array}$ & $\begin{array}{l}\text { Cementação, } \\
\text { nitretação }\end{array}$ & \\
\hline $\begin{array}{l}\text { Montagem e } \\
\text { ajustes }\end{array}$ & & & & & $\begin{array}{l}\text { Estruturas de } \\
\text { grandes } \\
\text { dimensões, } \\
\text { desalinhamentos } \\
\text { de uniões }\end{array}$ \\
\hline
\end{tabular}

\subsection{Furo-Cego}

O furo-cego é uma técnica bastante utilizada para medição de tensões residuais, por ser de fácil aplicação, na maior parte dos casos, ter uma relação custo-exatidão adequada, e por seus procedimentos de medição e tratamento de resultados normalizados. É um técnica considerada semi-destrutiva, pois o dano causado por sua execução é muito localizado, não comprometendo o pleno funcionamento do equipamento em questão.(PEIXOTO FILHO, 2004).

A usinagem de um furo na medição de tensões residuais pode ser associada a técnicas experimentais para determinação das redistribuições de tensões por ele causadas. Apesar de gerar redistribuição das tensões, não se verificou na literatura a influência desses furos na redução da tensão média. As tensões residuais trativas podem reduzir a performance podendo ocasionar falhas em uso. Estas podem aumentar a taxa de danos por fadiga. No entanto as tensões compressivas são, na maioria das vezes, benéficas.(PEIXOTO FILHO, 2004). Ao aplicar o furo-cego em determinada região da peça ou equipamento, este gera tensões compressivas que podem anular as tensões trativas existentes, podendo alavancar a performance da peça.

\section{MATERIAL E MÉTODO}

Para toda a simulação foi empregado o software SolidWorks versão 2013. Esse software contêm uma extensão chamada SimulationXpress, que será a ferramenta para avaliar o estudo da geometria das peças e perfis estruturais.

Inicialmente foi utilizado uma peça modelada no programa em escala reduzida de um tipo de prensa hidráulica. A matéria prima utilizada é uma chapa de aço A36 com espessura de $9,5 \mathrm{~mm}$ com dimensões de $250 \mathrm{~mm}$ por $300 \mathrm{~mm}$, como mostrado na Figura 2. A Tabela 2 apresenta a composição química do aço A36. 
TABELA 2 - Composição Química do Aço ASTM - A36. Fonte: Adaptado Norma ASTM A36

\begin{tabular}{|c|c|c|c|c|c|}
\hline \multicolumn{4}{|c|}{ Certificado de Qualidade (Composição Quimica) do aço ASTM - A36 } \\
\hline$\%$ \% & $\% \mathrm{Mn}$ & $\% \mathrm{P}$ & $\% \mathrm{~S}$ & $\% \mathrm{Cu}$ \\
\hline 0,25 & $\ldots$ & 0,04 & 0,05 & 0,40 & 0,20 \\
\hline \multicolumn{4}{|c|}{ Propriedades Mecânicas do aço ASTM - A36 } \\
\hline $\begin{array}{c}\text { Limite de Escoamento } \\
(\mathrm{MPa})\end{array}$ & $\begin{array}{c}\text { Resistência a Tração } \\
\text { (MPa) }\end{array}$ & Alongamento (\%) \\
\hline 250 & \multicolumn{2}{c|}{$400-550$} & \multicolumn{2}{c|}{20} \\
\hline
\end{tabular}

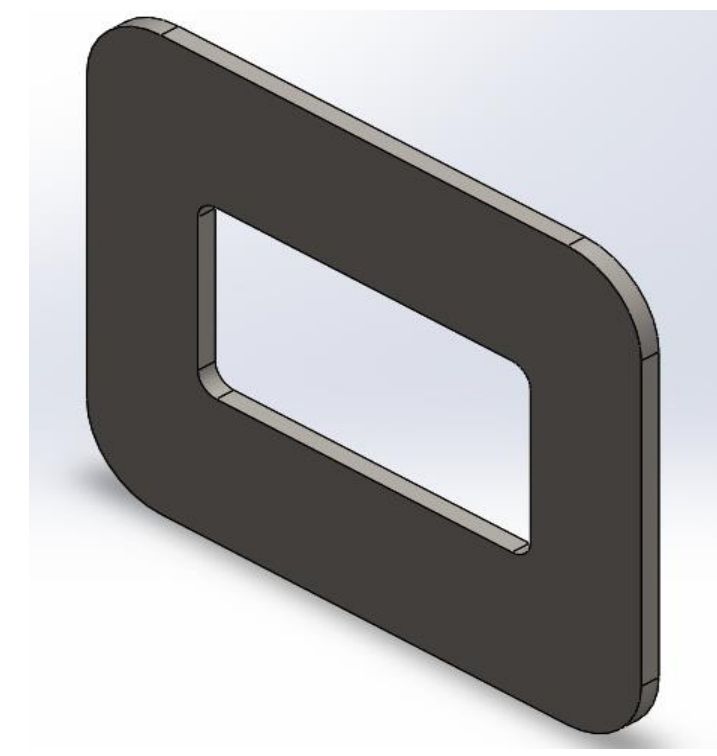

FIGURA 2 -Peça base modelada pelo software.

Fonte:AdaptadoSolidWorks versão 2013

Sem furos, apenas com uma abertura para que se possa simular os esforços exercidos, essa peça irá receber uma carga de $33.000 \mathrm{~N}$. Esse valor foi escolhido devido ao seu fator de segurança está próximo ao valor inicial $(F . S .=1)$ para essa carga. Na Figura 3 as forças estão representadas pelas setas rosas e suas restrições de movimento pelas setas verdes.

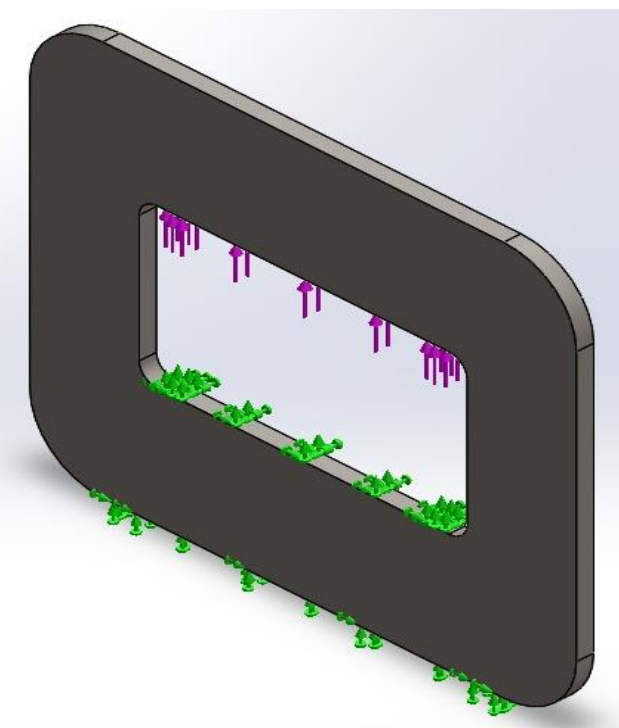

FIGURA 3 -Esquema das forças (rosa) e restrições de movimento (verde).

Fonte: Adaptado SolidWorks versão 2013 
Utilizando a ferramenta SimulationXpress e atribuindo os locais da carga e das restrições, pode-se simular como será a distribuição de tensões nessa peça e extrair informações como o F.S., que inicialmente será próximo de 1(um). A Figura 4 mostra a distribuição de tensões para o arranjo de forças e restrições pré-determinado.

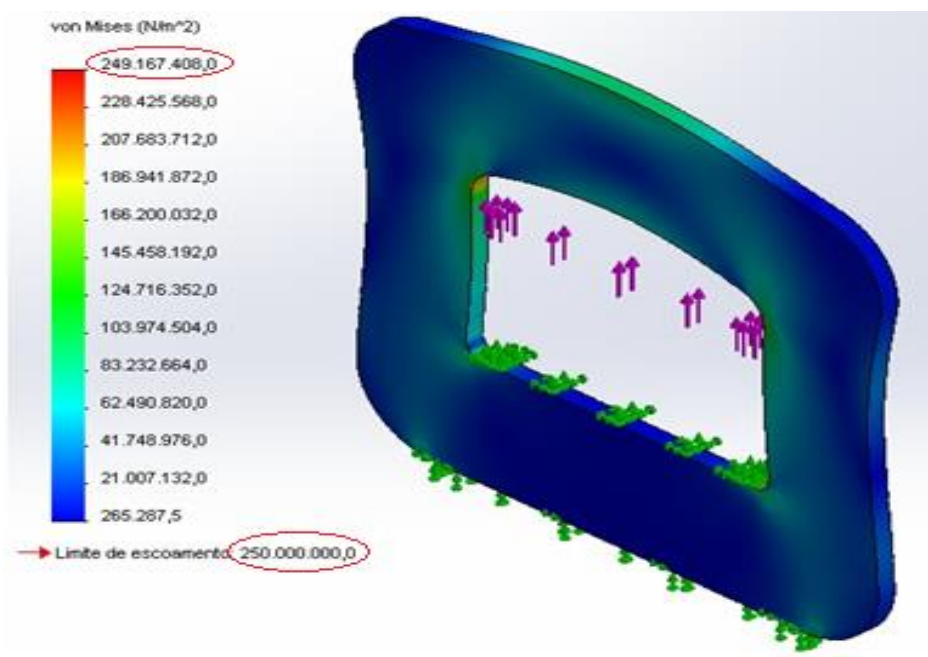

FIGURA 4 - Distribuição das tenções sobre a área da peça. Fonte: Adaptado SolidWorks versão 2013

Observa-se na Figura 4 que a tensão crítica mostrada no gráfico é de aproximadamente $250 \mathrm{MPa}$, que é próxima ao do limite de escoamento do material. Para essa simulação encontrou-se um valor do fator de segurança igual a 0,9967. Esse valor pode ser encontrado quando divide-se a tensão máxima encontrada na peça pelo limite de escoamento do material usado. Esses valores estão marcados na Figura 4. Com base nesses dados pode-se dar início a simulação inserindo os furos cegos em posições aleatórias e otimizar o arranjo das posições desses furos de acordo com os testes realizados.

\section{RESULTADOS E DISCUSSÕES}

Foram realizados seis testes até encontrar a quantidade, o diâmetro de cada furo e as posições ideais para um valor ótimo do fator de segurança. Cada teste foi inserido um par de furos com um valor pré-determinado de diâmetro e otimizado quanto as suas posições verticais e horizontais. A simulação foi realizada com o mesmo padrão do teste inicial. $\mathrm{Na}$ Tabela 3 pode-se observar o histórico de todos os testes realizados.

TABELA 3 - Histórico dos testes realizados e posicionamento dos furos. Fonte: Elaborado pelo Autor.

\begin{tabular}{|c|c|c|c|}
\hline Teste & Furos/Posição & F.S. & Melhoria \\
\hline 0 & Sem Furos & 0,997 & $0,00 \%$ \\
\hline 1 & 2 furos de $10 \mathrm{~mm}$ (posição inicial) & 1,036 & $3,79 \%$ \\
\hline 2 & 2 furos de $10 \mathrm{~mm}(x 1=-29,5 \mathrm{~mm} ; x 2=29,5 \mathrm{~mm} ; \mathrm{y}=90 \mathrm{~mm})$ & 1,048 & $4,89 \%$ \\
\hline 3 & 2 furos de $6 \mathrm{~mm}$ (posição inicial) & 1,065 & $6,41 \%$ \\
\hline 4 & $\begin{array}{l}2 \text { furos de } 10 \mathrm{~mm}(x 1=-29,5 \mathrm{~mm} ; x 2=29,5 \mathrm{~mm} ; \mathrm{y}=90 \mathrm{~mm})+ \\
2 \text { furos de } 6 \mathrm{~mm}(x 1=-60 \mathrm{~mm} ; x 2=60 \mathrm{~mm} ; \mathrm{y}=108,75 \mathrm{~mm})\end{array}$ & 1,071 & $6,93 \%$ \\
\hline 5 & 2 furos de $6 \mathrm{~mm}$ (posição inicial) & 1,072 & $7,02 \%$ \\
\hline 6 & $\begin{array}{l}2 \text { furos de } 10 \mathrm{~mm}(x 1=-29,5 \mathrm{~mm} ; x 2=29,5 \mathrm{~mm} ; \mathrm{y}=90 \mathrm{~mm})+ \\
2 \text { furos de } 6 \mathrm{~mm}(x 1=-60 \mathrm{~mm} ; x 2=60 \mathrm{~mm} ; \mathrm{y}=108,75 \mathrm{~mm}+2 \\
\text { furos de } 6 \mathrm{~mm}(x 1=-68,75 \mathrm{~mm} ; x 2=68,75 \mathrm{~mm} ; \mathrm{y}=-85 \mathrm{~mm})\end{array}$ & 1,083 & $7,96 \%$ \\
\hline
\end{tabular}


Para estes testes, determinou-se a posição de partida (origem). Esta posição serve para referenciar o posicionamento dos furos. Foi então realizado os testes. Cada teste com 2 furos posicionados simetricamente em relação a origem. Foram realizados 6 testes. Cada um apresentava um resultado, que servia de referência para o próximo teste. Esse método de estudo é conhecido com aproximação sucessiva.

A Figura 5 mostra a peça com os furos definidos (otimizados) e suas dimensões conforme sugerido pelo software e que foram apresentados na Tabela 3.

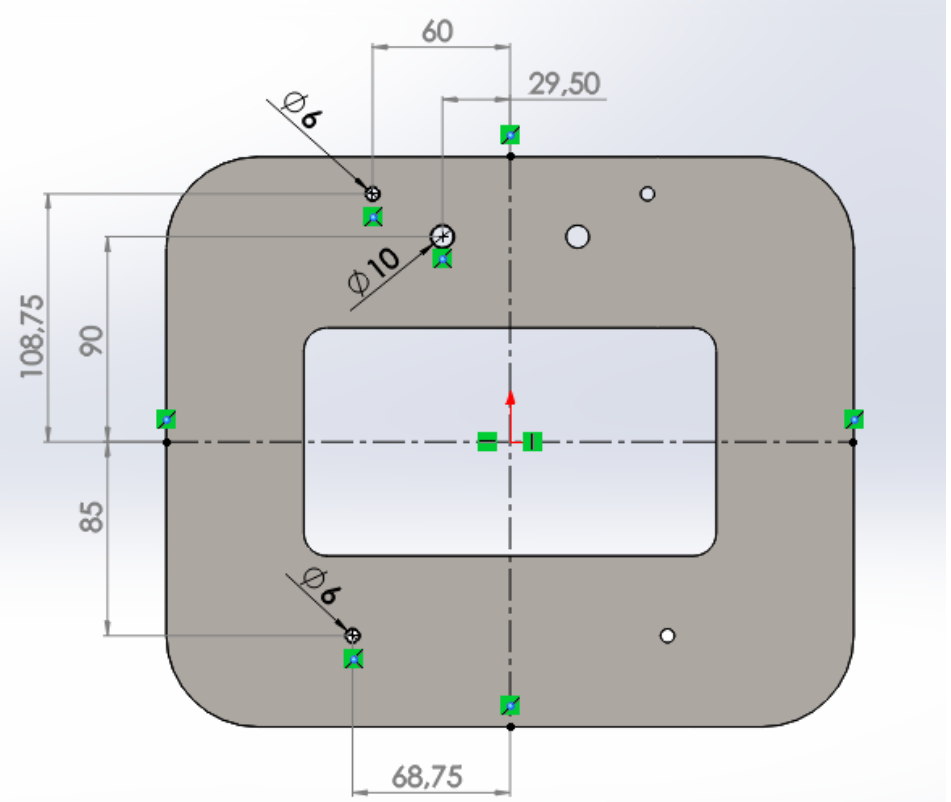

FIGURA 5 -Desenho esquemático com posicionamento e dimensão dos furos em relação a origem. Fonte: Adaptado SolidWorks versão 2013

A Figura 6 mostra o arranjo das forças e restrições de movimento como na peça com furos.

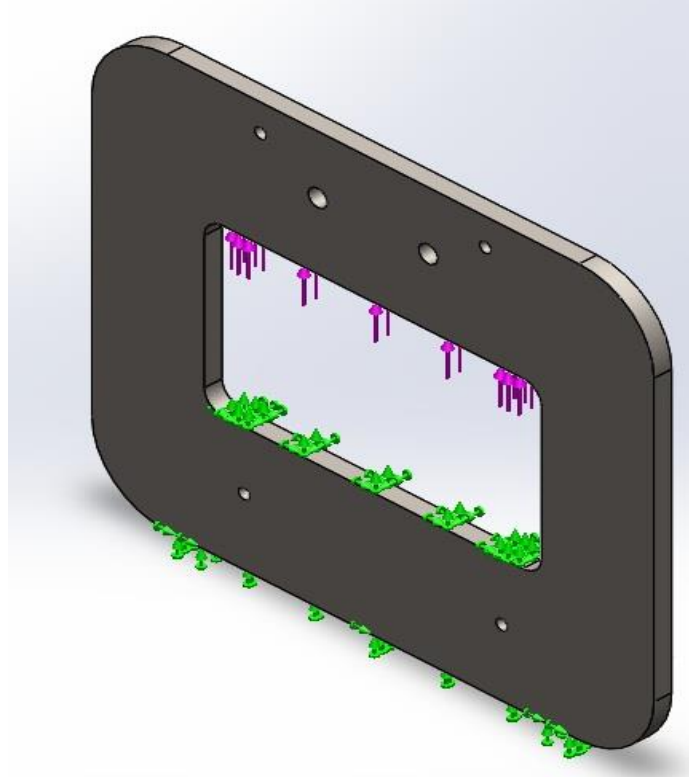

FIGURA 6 -Esquema das forças (rosa) e restrições de movimento (verde) na peça com furos.

Fonte: Adaptado SolidWorks versão 2013 
Como esperado após a usinagem dos furos a peça, que serve como objeto de teste para o estudo, obteve uma redução de sua tensão crítica, que inicialmente estava $249 \mathrm{MPa}$, passando para $231 \mathrm{MPa}$, esse valor pode ser observado no gráfico da Figura 7.

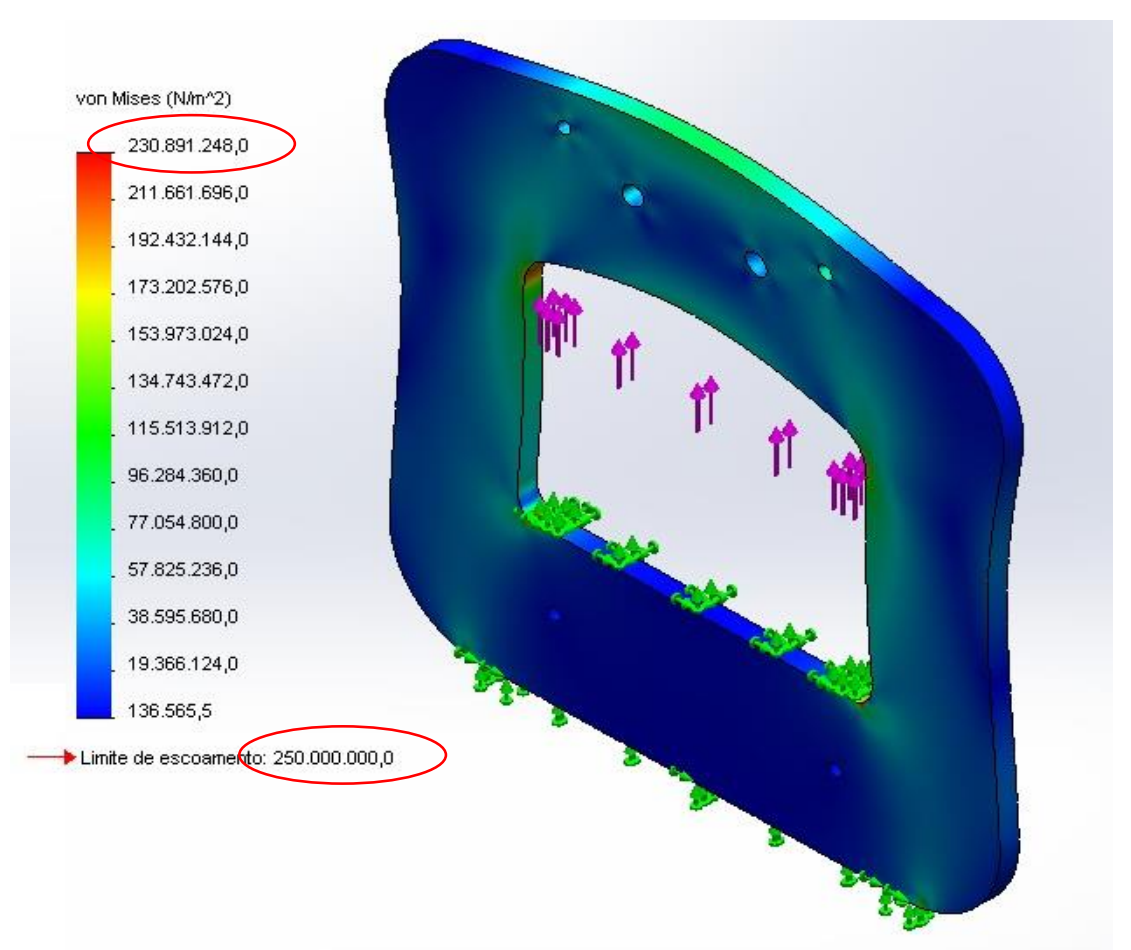

FIGURA 7 -Distribuição das tenções sobre a área da peça com furos.

Fonte: Adaptado SolidWorks versão 2013

A Figura 8 ilustra o aumento do fator de segurança da peça. Esse aumento está diretamente relacionado a capacidade da peça suportar maiores tensões do que as aplicadas inicialmente.

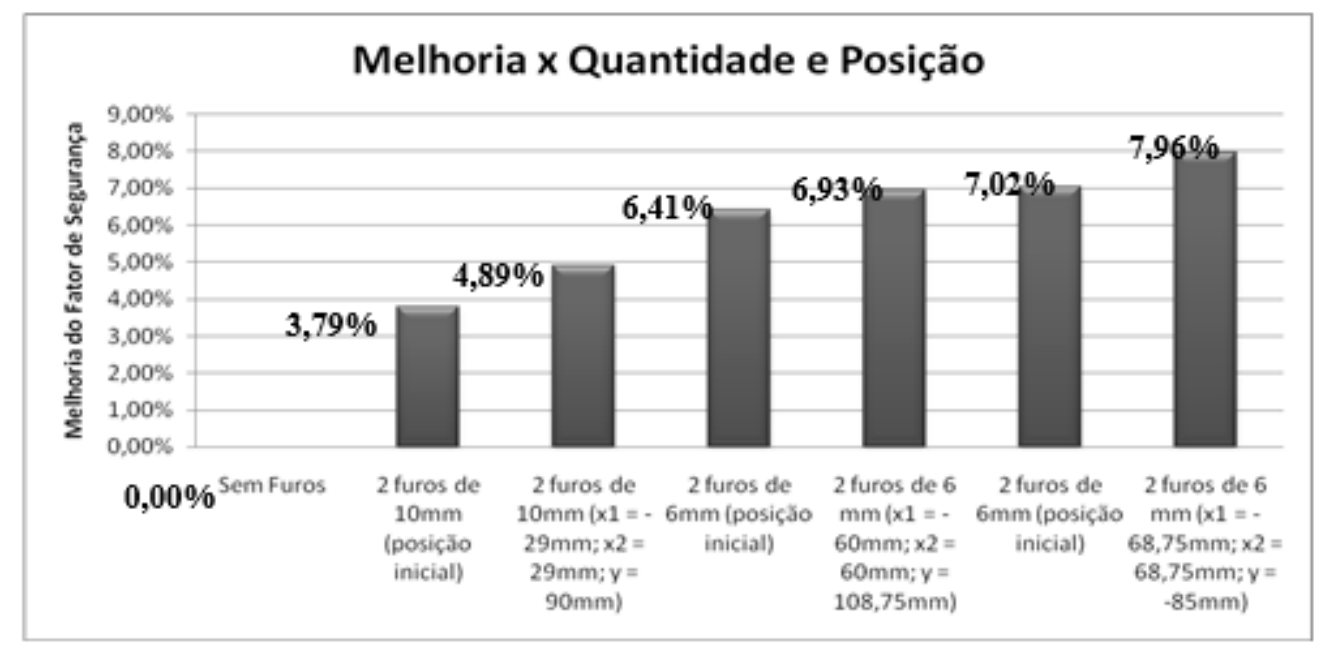

FIGURA 8 - Gráfico: Melhoria x Quantidade e Posicionamento. Adaptado SolidWorks versão 2013 


\section{CONCLUSÕES}

Pelo apresentado no trabalho pode-se tirar as seguintes conclusões:

- O emprego dos furos cegos reduzem em aproximadamente $8 \%$ a tensão média;

- O posicionamento dos furos interferem diretamente no resultado, logo, deve-se encontrar sua posição ótima;

- Apesar de pouco empregado, esta técnica demonstrou ser eficaz para a redução de tensões médias.

\section{REFERÊNCIAS}

SOARES, MARIA DA CONCEIÇÃO B. VIEIRA; "Influência das tensões residuais no comportamento em fadiga e fratura de ligas metálicas", Dissertação de Doutorado, Instituto de Pesquisas Energéticas e Nucleares, 1998.

DIETER, G. E, "Mechanical Metallurgy", Mc Graw Hill Kagakusha, 1976.

FILHO, FLÁVIO TITO PEIXOTO; "Avaliação de Sistemas de Medição de Tensões e Tensões Residuais em Dutos”, Dissertação de Mestrado, Universidade Federal de Santa Catarina, 2004.

PUC-Rio - Certificação Digital № 99166773/CA. "Técnica do Furo-Cego para Medição de Tensões Residuais." <http://www.maxwell.vrac.pucrio.br/4411/4411_4.PDF> Acessado em:14/05/2015.

ASTM STANDAR̄DS. "ASTM A 36: Standard Specification for Carbon Structural Steel." <https://law.resource.org/pub/us/cfr/ibr/003/astm.a36.1997.pdf> Acessado em: 18/05/2015. 